\title{
NUBŻAH AL-BAYÃN SEBAGAI SOLUSI MENGUASAI KETERAMPILAN MEMBACA KITAB KLASIK/KITAB KUNING
}

\author{
Siti Sulaikho \\ Universitas KH. Wahab Hasbullah \\ ikho_zul@unwaha.ac.id
}

\begin{abstract}
Abstrak
Penelitian ini bertujuan untuk menganalisis Nubżah al-Bayãn sebagai solusi bagi santri di Lembaga Pendidikan Islam Maktab Nubdatul Bayan Al-Majidiyah (LPI Maktuba AlMajidiyah) untuk dapat membaca kitab klasik/kitab kuning dalam waktu singkat. Pertanyaan dalam penelitian ini adalah apa yang dimaksud dengan Nubżah al-Bayãn dan bagaimana para santri di LPI Maktuba Al-Majidiyah mampu membaca kitab kuning dalam waktu singkat dengan menggunakan Nubżah al-Bayãn. Penelitian ini menggunakan pendekatan kualitatif dengan metode studi kasus. Temuan penelitian ini menunjukkan bahwa Nubżah al-Bayãn merupakan rangkuman dari 5 kitab tatabahasa Arab, yaitu al-'Imrĩtĩ, Alfiyah Ibn Mãlik, Qawa'id al-I'rab, al-Maqsũd, dan Nubżah yang dikarang oleh KH. Abdul Majid bin Abdul Hamid. Nubżah al-Bayãn terdiri dari 7 buku kecil, yaitu 5 jilid buku pokok, 1 jilid Takmilah al-Bayãn sebagai penyempurna dan 1 jilid Anzimah al-Bayãn yang berisi kumpulan nazam. Masing-masing dari 5 jilid buku pokok ditempuh dalam 25 hari, sedangkan Takmilah al-Bayãn ditempuh dalam 1 bulan. Anżimah al-Bayãn dipelajari bersamaan dengan buku pokok dan Takmilah al-Bayãn. Kelas yang terdiri dari kelompok kecil, peserta didik yang dituntut untuk aktif dan bersaing, serta sistem percepatan pada setiap kelas mampu membuat para santri menguasai keterampilan membaca kitab klasik/kitab kuning dalam waktu yang lebih singkat.
\end{abstract}

Kata Kunci: Nubżah al-Bayãn, santri, membaca, kitab kuning

\section{Pendahuluan}

Dunia pesantren, dengan meminjam kerangka Hossein Nasr, adalah dunia tradisional Islam, yaitu dunia yang mewarisi dan memelihara kontiunitas tradisi 


\section{Siti Sulaikho}

Islam, yang dikembangkan ulama dari masa ke masa, tidak terbatas pada periode tertentu dalam sejarah Islam. ${ }^{1}$

Pesantren yang merupakan pusat pembelajaran studi Islam adalah lembaga pendidikan tradisional asli Indonesia. ${ }^{2}$ Nurcholish Madjid bahkan menegaskan bahwa pesantren adalah artefak peradaban Indonesia yang dibangun sebagai institusi pendidikan keagamaan bercorak tradisional, unik dan indigenous (asli Indonesia). ${ }^{3}$

Para peneliti sepakat bahwa pesantren adalah lembaga pendidikan tradisional asli Indonesia. Mereka hanya berbeda pendapat dalam hal proses lahirnya pesantren. Perbedaan pendapat ini digolongkan menjadi dua kelompok.

Kelompok pertama berpendapat bahwa pesantren merupakan hasil kreasi sejarah anak bangsa setelah mengalami persentuhan budaya dengan budaya praIslam (Hindu-Budha). Kelompok ini berasumsi bahwa pesantren memiliki persamaan dengan mandala dan asrama yang sudah ada semenjak zaman HinduBudha. Persamaan lainnya adalah letak dan posisi keduanya yang cenderung mengisolasi diri dari pusat keramaian, adanya ikatan “kebapakan” antara guru dan murid sebagaimana ditunjukkan kyai dan santri, serta kebiasaan berkelana (uzlah) guna melakukan pencarian ruhani dari satu tempat ke tempat lainnya.

1 Azyumardi Azra, "Pesantren Kontiunitas dan Perubahan" dalam Nurcholis Madjid, Bilik-bilik Pesantren: Sebuah Potret Perjalanan (Jakarta: Paramadina, 1997), xxiv.

${ }^{2}$ HM. Amin Haedari, dkk., Masa Depan Pesantren: dalam Tantangan Modernitas dan Tantangan Kompleksitas Global (Jakarta: IRD Press, 2004), 2.

${ }^{3}$ Nurcholish Madjid, Bilik-bilik Pesantren, 10. 
Kelompok kedua berpendapat bahwa pesantren diadopsi dari lembaga pendidikan Timur-Tengah. Kelompok ini berasumsi bahwa pesantren cenderung lebih dekat dengan salah satu model pendidikan di Al-Azhar. Selain itu, pesantren merupakan kombinasi antara madrasah dan pusat kegiatan tarekat, bukan antara Islam dengan Hindu-Budha. ${ }^{4}$

Dalam tradisi pesantren, terdapat lima elemen dasar, yaitu pondok, masjid, kyai, santri dan pengajaran kitab-kitab Islam klasik atau kitab kuning. ${ }^{5}$ Pengajaran kitab-kitab klasik atau kitab kuning pada pesantren umumnya menggunakan model bandongan/wetonan dan sorogan. ${ }^{6}$ Kedua metode ini lebih sering disebut dengan pengajian. ${ }^{7}$

Hambatan yang ditemukan dalam mempelajari kitab klasik/kitab kuning adalah dibutuhkan waktu yang cukup lama untuk dapat membaca, terlebih memahami isinya. Terdapat jenjang kitab-kitab nahwu dan șaraf yang harus dipelajari secara berurutan. Tidak mengherankan jika santri yang memahami kitab klasik/kitab kuning adalah para santri senior yang telah mempelajarinya selama bertahun-tahun.

Kedua paradigma di atas menjadi landasan bagi para pelaku pendidikan di Lembaga Pendidikan Islam Maktab Nubdatul Bayan Al-Majidiyah (LPI Maktuba AlMajidiyah) untuk menyusun Nubżah al-Bayãn Fĩ Tashîli Ma'rifati Qawã'idi Siyaqi wa Kalãmi Ahli al-'Irfãn atau Nubżah al-Bayãn untuk dapat mempelajari kitab-kitab

\footnotetext{
${ }^{4}$ HM. Amin Haedari, dkk., Masa Depan Pesantren, 2-4.

${ }^{5}$ Zamakhsyari Dhofier, Tradisi Pesantren: Studi tentang Pandangan Hidup Kyai (Jakarta: LP3ES, 1982), 44.

${ }^{6}$ Muhtarom, Reproduksi Ulama di Era Globalisasi (Yogyakarta: Pustaka Pelajar, 2005), 8.

${ }^{7}$ Nurcholish Madjid, Bilik-bilik Pesantren, 23.
} 


\section{Siti Sulaikho}

klasik/kitab kuning menjadi lebih mudah serta tidak membutuhkan waktu yang lama.

Penelitian ini berupaya menjawab dan menganalisis apakah yang dimaksud dengan Nubżah al-Bayãn Fũ Tashĩli Ma'rifati Qawã'idi Siyaqi wa Kalãmi Ahli al-'Irfãn dan bagaimana Nubżah al-Bayãn mampu menjadi solusi agar para santri dapat membaca kitab klasik/kitab kuning dalam waktu yang lebih singkat.

\section{Metode Penelitian}

Penelitian ini menggunakan pendekatan kualitatif dikarenakan lebih mengarah ke penelitian proses daripada produk. Adapun metode yang digunakan adalah studi kasus. Alasan memilih studi kasus dalam penelitian ini adalah karena strategi yang lebih cocok apabila pokok pertanyaan berkaitan dengan "how" atau "why" adalah studi kasus.

Sumber data terbagi menjadi dua, yaitu sumber primer dan sumber sekunder. Sumber data utama dalam penelitian ini adalah hasil wawancara dengan yang diteliti dan hasil pengamatan berperanserta. Adapun sumber data pendukung atau data sekunder dalam penelitian ini adalah buku Nubżah al-Bayãn, arsip, serta buku-buku yang berkaitan.

Dalam penelitian ini, yang menjadi instrumen penelitian adalah peneliti sendiri sebagai human instrument yang berfungsi menetapkan fokus penelitian, memilih informan sebagai sumber data, melakukan pengumpulan data, menilai 


\section{Nubżah Al-Bayãn Sebagai Solusi Menguasai Keterampilan}

Membaca Kitab Klasik/Kitab Kuning

kualitas data, analisis data, menafsirkan data dan membuat kesimpuan atas temuannya.

Adapun teknik pengumpulan data yang digunakan oleh peneliti adalah pengamatan terhadap aktifitas pelaku pendidikan di LPI Maktuba Al-Majidiyah, wawancara terhadap tim penyusun buku Nubżah al-Bayãn, penanggung jawab LPI Maktuba Al-Majidiyah yang merupakan lembaga pelaksana Nubżah al-Bayãn, pengurus lembaga, serta anak didik di lembaga tersebut. Teknik pengumpulan data lainnya yang dilakukan oleh peneliti adalah dokumentasi dan triangulasi. Dokumentasi berupa buku Nubżah al-Bayãn, dan tes tulis yang berlaku di LPI Maktuba Al-Majidiyah, sedangkan triangulasi yang dipilih adalah triangulasi teknik.

Analisis data dalam penelitian ini meliputi: (a) reduksi data yang berupa merangkum data-data yg diperoleh, memilih hal-hal yang pokok, memfokuskan pada hal-hal yang penting, serta mencari tema dan pola dari keseluruhan data yang diperoleh di lapangan. Setelah data direduksi, langkah selanjutnya adalah (b) menyajikan data dalam bentuk uraian singkat, bagan, hubungan antar kategori, flowchart, dan sebagainya. Langkah ketiga adalah (c) penarikan kesimpulan dan verifikasi.

\section{Pendidikan di Pesantren}

Muhammad Arifin mengkategorikan elemen penting pendidikan pesantren menjadi dua, yaitu infrastruktur dan suprastruktur. Infrastruktur meliputi perangkat 


\section{Siti Sulaikho}

lunak (software) dan perangkat keras (hardware). Perangkat lunak (software) terdiri dari kurikulum dan metode pembelajaran. Perangkat keras (hardware) meliputi pondok, masjid, sarana dan prasarana belajar. Sedangkan suprastruktur pesantren meliputi kyai, santri, pengasuh, yayasan dan para pembantu kyai atau ustad. ${ }^{8}$

Pendapat Mastuhu tidak jauh berbeda dengan M. Arifin. Hanya saja Mastuhu memakai istilah "aktor" sebagai pengganti suprastruktur. Selain itu, Mastuhu membatasi hanya kyai dan santri sebagai aktor pesantren, tanpa menyertakan pengasuh, yayasan dan para pembantu kyai atau ustad. Perbedaan lainnya adalah, Mastuhu menambahkan tujuan pembelajaran dan evaluasi ke dalam perangkat lunak. Dengan demikian perangkat lunak terdiri dari 5 unsur, yaitu tujuan, kurikulum, metode pembelajaran, evaluasi dan alat-alat penunjang lainnya. ${ }^{9}$

Mendahului keduanya, Zamakhsyari Dhofir menyebutkan bahwa pesantren memiliki lima elemen dasar, yaitu pondok, masjid, santri, pengajaran kitab-kitab Islam klasik atau kitab kuning dan kyai. ${ }^{10}$

Kitab kuning adalah istilah yang ditujukan untuk buku karangan atau hasil karya para ulama pada abad pertengahan yang ditulis dengan bahasa Arab dan berisi pemikiran mereka tentang masalah agama. Disebut kitab kuning, karena kertas yang digunakan untuk menulis berwarna kuning. Setelah mengalami kemajuan, sudah banyak yang tidak menggunakan kitab dengan kertas berwarna kuning. Di kalangan

\footnotetext{
${ }^{8}$ M. Arifin, Kapita Selekta Pendidikan Islam dan Umum (Jakarta: Bina Aksara, 1995), 257

${ }^{9}$ Mastuhu, Dinamika Sistem Pendidikan Pesantren (Jakarta: INIS, 1994), 55-56.

${ }^{10}$ Zamakhsyari Dhofier, Tradisi Pesantren, 44.
} 
santri sendiri sudah jarang yang menyebut istilah kitab kuning, tapi cukup menunjuk nama kitab secara langsung. ${ }^{11}$

Pengajaran kitab kuning di pesantren menggunakan metode bandongan/wetonan dan sorogan. ${ }^{12}$ Bandongan/wetonan adalah metode pengajaran kolektif dimana santri bersama-sama mendengarkan ustad atau kyai yang membaca, menterjemahkan, menerangkan dan mengulas kitab tertentu. ${ }^{13}$ Sorogan merupakan model pengajaran individual. Dalam aplikasinya, santri mendatangi ustad atau kyai supaya ustad atau kyai tersebut mendengarkan sekaligus memberikan koreksi terhadap bacaan kitab mereka. ${ }^{14}$

Dalam bandongan/wetonan, kyai memiliki peranan yang dominan. Kyai yang berinisiatif dalam menentukan waktu, tempat, maupun kitabnya. Sedangkan sorogan adalah kebalikan dari bandongan/weton. Yang memiliki permintaan adalah seorang atau beberapa santri kepada kyainya. ${ }^{15}$

\section{Penyusunan Nubżah al-Bayãn}

Pada tahun 2005, Kyai Abdul Mu'in Muhammad Bayan AMZ atau lebih sering dipanggil dengan Kyai Bayan, salah satu pengasuh Pondok Pesantren Mamba'ul Ulum, Batabata, Madura, mempunyai inisiatif membuat metode supaya dapat membaca kitab dengan cepat. Tiga santri senior di pondok tersebut dipanggil

\footnotetext{
${ }^{11}$ M. Dawam Rahardjo, Pergulatan Dunia Pesantren (Jakarta: P3M, 1985), 55.

${ }^{12}$ Muhtarom, Reproduksi Ulama, 8.

${ }^{13}$ Anin Nurhayati, Kurikulum Inovasi: Telaah terhadap Pengembangan Kurikulum Pendidikan Pesantren (Yogyakarta: Teras, 2010), 54.

${ }^{14}$ HM. Amin Haedari, dkk., Masa Depan Pesantren, 16.

${ }^{15}$ Ibid.
} 


\section{Siti Sulaikho}

untuk merealisasikan inisiatif dari Kyai Bayan. Ketiga orang yang dimaksud adalah ustad 'Allamul ‘Ulya, ustad 'Abdul Lathif dan ustad Nur Kholis.

Ketiga orang yang disebut sebagai Tim Penyusun tersebut membuat rancangan sistematika dari buku yang akan menjadi acuan dari metode yang dimaksudkan oleh Kyai Bayan.

Pada hari ketujuh, Tim Penyusun menghadap Kyai Bayan dengan membawa rancangan sistematika yang telah mereka susun. Masing-masing Tim Peneliti memiliki tanggung jawab yang berbeda. Ustad Abdul Lathif lebih berperan dalam penyusunan sistematika dan materi, ustad 'Allamul Ulya memberi tambahantambahan yang tidak ditemukan dalam Amșilati, dan pengetikan menjadi tanggung jawab ustad Nur Kholis. Proses pengetikan berlangsung selama 2 bulan.

Ketika rancangan sistematika yang mereka susun diserahkan, Kyai Bayan mengoreksi, menambah keterangan-keterangan yang kurang, mengurangi bagianbagian yang dianggap berlebih, serta menyusun ulang sistematika yang masih dirasa kurang sesuai. Kyai Bayan juga-lah yang memberi nama rancangan buku acuan metode cepat membaca kitab dengan Nubżah al-Bayãn Fĩ Tashîli Ma'rifati Qawã'idi Siyaqi wa Kalãmi Ahli al-`Irfãn atau lebih sering disebut dengan Nubżah al-Bayãn.

Setelah selesai dikoreksi oleh Kyai Bayan, Nubżah al-Bayãn dihaturkan kepada kedua kakak beliau yang juga pengasuh pesantren Mamba'ul Ulum, yaitu Kyai Abdul Hamid AMZ dan Kyai Abdul Qadir AMZ untuk dikoreksi kembali dan mendapatkan persetujuan. 
Pengenalan Nubżah al-Bayãn dilakukan bersamaan dengan wisuda TK milik Pondok Pesantren Mamba'ul Ulum di tahun yang sama. Respon positif ditunjukkan oleh masyarakat yang meminta segera direalisasikannya program Nubżah al-Bayãn. Akan tetapi Nubżah al-Bayãn tidak langsung diajarkan pada ajaran baru di tahun itu.

Permintaan masyarakat yang semakin banyak mendorong Kyai Bayan dan kedua pengasuh Batabata mendirikan gedung khusus yang diperuntukkan bagi santri yang hendak mempelajari Nubżah al-Bayãn. Selama proses pembangunan, Nubżah al-Bayãn sama sekali tidak diajarkan.

Pada tahun 2007 akhir, program Nubżah al-Bayãn terealisasikan untuk yang pertama kalinya, setelah pembangunan gedung untuk mempelajari Nubżah al-Bayãn selesai. Wisuda pertama angkatan ini berlangsung pada tahun 2008. Jumlah santri yang mengikuti wisuda pertama adalah 11 orang. Wisuda kedua diikuti 31 orang, dan wisuda ketiga diikuti oleh lebih dari 100 orang. Hingga sekarang, jumlah santri yang telah diwisuda Nubżah al-Bayãn telah lebih dari 1.000 orang.

\section{Materi Nubżah al-Bayãn}

Nubżah al-Bayãn terdiri dari dari 5 jilid buku pokok, 1 jilid Takmilah al-Bayãn sebagai penyempurna dan 1 jilid Anżimah al-Bayãn yang berisi kumpulan nazam. Nubżah al-Bayãn merangkum 5 kitab, yaitu Alfiyah Ibn Mãlik, al-'Imrĩți, Nubżah (nama kitab yang lain), al-Maqsud dan Qawa'id al-I'rab. Meskipun rangkuman, bukan berarti Nubżah al-Bayãn adalah buku kecil yang bisa dipelajari sekali duduk. Masing-masing 


\section{Siti Sulaikho}

jilid dalam buku ini idealnya membutuhkan waktu 25 hari, kecuali Takmilah al-Bayãn yang ditempuh dalam waktu 1 bulan. Sedangkan Anz̧imah al-Bayãn dipelajari bersamaan dengan kedua buku lainnya.

Takmilah al-Bayãn adalah penyempurna dari kelima jilid Nubżah al-Bayãn. Yang dimaksud penyempurna disini adalah penjabaran dari teori-teori yang disebutkan singkat dalam Nubżah al-Bayãn. Oleh karena itu topik dari Takmilah alBayãn tidak berbeda dengan topik yang dibahas dalam masing-masing jilid Nubżah alBayãn.

\section{Evaluasi Nubżah al-Bayãn}

Evaluasi yang dilakukan di LPI Maktuba Al-Majidiyah berupa tes diagnostik dan tes sumatif. Tes diagnostik dilakukan selama proses pembelajaran berlangsung, baik pre-test maupun post-test. Tes sumatif dilakukan pada maksimal 25 hari untuk meyelesaikan materi Nubżah al-Bayãn yang memiliki 6 kelas. Apabila peserta didik menyelesaikan materinya sebelum 25 hari, diperbolehkan melaksanakan tes sumatif lebih awal dan melanjutkan ke kelas selanjutnya apabila lulus.

Tes sumatif kelas Takmilah al-Bayãn ditempuh maksimal setelah 1 bulan proses pembelajaran. Apabila peserta didik menyelesaikan materinya sebelum waktu 1 bulan, diperbolehkan melaksanakan tes sumatif lebih awal dan melanjutkan ke kelas Praktek 1 apabila lulus. 


\section{Nubżah Al-Bayãn Sebagai Solusi Menguasai Keterampilan \\ Membaca Kitab Klasik/Kitab Kuning}

Bentuk tes yg berlaku adalah tes tulis dan tes lisan. Apabila salah satu tes tidak lulus, maka yang diulang adalah kedua tes tersebut, bukan salah satunya.

\section{Simpulan}

Penggunaan Nubżah al-Bayãn F̃̃ Tashîli Ma'rifati Qawã'idi Siyaqi wa Kalãmi Ahli al-'Irfãn atau Nubżah al-Bayãn mampu membuat para santri menjadi lebih cepat dalam menguasai keterampilan membaca kitab klasik/kitabkuning. Hal ini disebabkan olel beberapa faktor.

Pertama, Nubżah al-Bayãn adalah rangkuman dari 5 kitab tatabahasa Arab sehingga dengan mempelajari Nubżah al-Bayãn, sama dengan mempelajari 5 kitab sekaligus. Isi dari Nubżah al-Bayãn adalah saling melengkapi. Apabila suatu keterangan tidak ditemukan dalam 1 kitab tertentu, akan ditemukan pada kitab lainnya.

Kedua, isi Nubżah al-Bayãn adalah singkat dan fokus. Kaidah dijabarkan sekaligus dalil yang menunjukkan kaidah tersebut. Keterangan diberikan sebagai penunjang pemahaman dan disajikan dengan tidak melebar ke bab-bab yang lain.

Ketiga, kelas Nubżah al-Bayãn berupa kelompok-kelompok kecil antara 10-12 anak dengan 1 pembimbing. Dengan jumlah peserta didik yang tidak banyak dalam setiap kelompok, memungkinkan pembimbing untuk mengamati dan memperhatikan perkembangan masing-masing peserta didik dengan maksimal. 


\section{Siti Sulaikho}

Keempat, proses belajar Nubżah al-Bayãn lebih banyak dilakukan oleh peserta didik. Pembimbing hanya menyimak, memberi keterangan tambahan dan membenarkan peserta didik yang melakukan kesalahan. Dalam setiap pertemuan, pembimbing selalu mengecek tingkat pemahaman masing-masing peserta didik secara bergantian. Kontinuitas dalam proses belajar yang seperti ini sangat berpengaruh pada peserta didik dalam penguasaan materi yang.

Kelima, Nubżah al-Bayãn memiliki batas maksimal hari untuk mempelajarinya dalam setiap jilid. Masing-masing dari kelima jilid pokok Nubżah al-Bayãn harus dikuasai maksimal 25 hari. Jika dalam 25 hari belum berhasil menguasai jilid tertentu, maka harus mengulang jilid tersebut dari awal.

Keenam, terdapat sistem percepatan dalam mempelajari Nubżah al-Bayãn. Sistem percepatan yang dimaksud adalah peserta didik diperbolehkan mengikuti ujian tes kenaikan jilid meskipun belum mencapai 25 hari. Dengan adanya sistem ini, masing-masing peserta saling berlomba dalam hal pencapaian materi. Meskipun berada di kelas yang sama, bisa jadi perolehan materi yang dikuasai berbeda. 


\section{Nubżah Al-Bayãn Sebagai Solusi Menguasai Keterampilan \\ Membaca Kitab Klasik/Kitab Kuning}

\section{DAFTAR PUSTAKA}

Arifin, M., Kapita Selekta Pendidikan Islam dan Umum. Jakarta: Bina Aksara, 1995.

Dhofier, Zamakhsyari, Tradisi Pesantren: Studi tentang Pandangan Hidup Kyai. Jakarta: LP3ES, 1982.

Haedari, HM. Amin, dkk., Masa Depan Pesantren: dalam Tantangan Modernitas dan Tantangan Kompleksitas Global. Jakarta: IRD Press, 2004.

Madjid, Nurcholish, Bilik-bilik Pesantren: Sebuah Potret Perjalanan. Jakarta: Paramadina, 1997.

Mastuhu, Dinamika Sistem Pendidikan Pesantren. Jakarta: INIS, 1994.

Muhtarom, Reproduksi Ulama di Era Globalisasi. Yogyakarta: Pustaka Pelajar, 2005.

Nurhayati, Anin, Kurikulum Inovasi: Telaah terhadap Pengembangan Kurikulum Pendidikan Pesantren. Yogyakarta: Teras, 2010.

Rahardjo, M. Dawam. Pergulatan Dunia Pesantren. Jakarta: P3M, 1985. 
Siti Sulaikho

46 | Dinamika Vol. 3, No. 1, Juni 2018 